\title{
The interplay between risk and protective factors during the initial height of the COVID-19 crisis in Italy: The role of risk aversion and intolerance of ambiguity on distress
}

\author{
S. Petrocchi ${ }^{1}$ (D) P. Iannello ${ }^{2} \cdot$ G. Ongaro ${ }^{1,3} \cdot$ A. Antonietti ${ }^{2} \cdot$ G. Pravettoni ${ }^{1,3}$ \\ Accepted: 10 March 2021 / Published online: 19 March 2021 \\ (C) The Author(s), under exclusive licence to Springer Science+Business Media, LLC, part of Springer Nature 2021Abstract
}

The present study aimed to test a model of relations to ascertain the determinants of distress caused by lockdown for COVID19. It was hypothesized that the exposure to the COVID-19 increased distress directly and through the mediation of worry, health-related information seeking, and perception of the utility of the lockdown. It was also expected that higher levels of ambiguity intolerance corresponded to higher distress directly and through the mediation of worry, health information seeking behaviors, and perceived utility of the lockdown. Finally, it was expected that risk aversion positively influenced distress directly and through the increasing of worry, health-related information seeking behavior, and more positive perception of the utility of the lockdown The study was conducted in Italy during the mandatory lockdown for COVID-19 pandemic on 240 individuals (age range 18-76). Data recruitment was conducted via snowball sampling. COVID-19 exposure was positively associated with worry and health-related information seeking. Risk-aversion was positively associated with health-related information seeking and perceived utility of the lockdown to contain the spread of the virus. Worry and health-related information seeking were positively associated with distress, whereas the perceived utility of the lockdown was negatively associated with distress. Intolerance for the ambiguity was directly linked to distress with a positive sign. Findings suggest that risk aversion represents both a risk factor and a protective factor, based on what kind of variable mediates the relationship with distress, and that the intolerance to the ambiguity is a risk factor that busters distress.

Keywords Risk-aversion · Ambiguity tolerance · COVID-19 - Psychological distress · Information seeking · Worry · Psychological Distress during COVID-19 Pandemic: The Interplay between Protective and Risk Factors

\section{Background}

According to the European Center for Disease Prevention and Control (ECDC, 2020a) since 31 December 2019, 8.000.847 cases of COVID-19 have been reported worldwide, including 436.632 deaths. Caused by the virus SARS-CoV-2, the WHO has declared COVID-19 as a pandemic in March 2020. In Italy, in March and April 2020, the time in which the present

S. Petrocchi

serena.petrocchi@ieo.it

1 Applied Research Division for Cognitive and Psychological Science, European Institute of Oncology IRCCS, Via Ripamonti, 435, 20132 Milan, MI, Italy

2 Department of Psychology, Catholic University of the Sacred Heart, Milan, Italy

3 Department of Oncology and Hemato-Oncology (DIPO), University of Milan, Milan, Italy study was carried out, the official number of cases reached 110.574 with 13.157 deaths. In the same period, in the U.S. the cases were $216.721,102.136$ in Spain, 73.522 in Germany, 56.989 in France, 29.474 in the United Kingdom (ECDC, 2020b). In response to the increasing number of infections and deaths, European countries have implemented non-pharmaceutical measures including social distancing, border closures, school closures, isolation measures for symptomatic individuals and their contacts, and the lockdown of the population with internal travel banned. In Italy, the lockdown started on March 8, ended on May 18, and involved almost the entire population.

The lockdown was found to be effective in reducing quickly the spread of the virus (Nussbaumer-Streit et al., 2020). However, the review of the studies carried out during previous pandemics (e.g. SARS, Ebola, H1N1 influenza) revealed a negative psychological impact generated by physical isolation and quarantine (Brooks et al., 2020; Rubin \& Wessely, 2020). Short-term effects involved emotional disorders, anxiety, depression, stress, mood decline, irritability, insomnia, and 
PTSD. Other authors (Ahmed et al., 2020; Di Giuseppe et al., 2020; Gualano et al., 2020; Hossain et al., 2020; Mazza et al., 2020) reported a high burden of mental health conditions among individuals who experienced isolation and quarantine, including anxiety, depression, anger, irritability, alcohol use disorder, reduced sleep quality, and psychosocial distress. Evidence suggested that such impacts continued over a long period, after the end of the lockdown, highlighting that acute exposure to psychosocial stressors during quarantine and social isolation can exert prolonged impacts on the psychological functioning and mental health (Fernández et al., 2020; Park \& Park, 2020; Shigemura et al., 2020). What is still to be identified is the determinants of the mental distress and the mechanisms underlined to it. The present study aimed to analyze several mechanisms to detect both protective and risk factors in predicting psychological distress during the lockdown due to COVID-19 outbreak. The American Psychological Association defines psychological distress as a combination of mental and physical symptoms associated with normal fluctuations of mood (VandenBos, 2015). Distress includes states of worry, tension, unhappiness, pessimism, sadness (Harvey \& Bray, 1991) and symptoms of depression and anxiety (Arvidsdotter et al., 2016; Bhattacharyya et al., 2014). In order to address and cope with the source of distress, emotional or behavioral regulation strategies could be used, such as positive reframing, mindfulness, acceptance or humor (Coffey \& Hartman, 2008; Mauri et al., 2018; Powell, 2018).

\section{The Association between Covid-19 Direct Exposure and Distress}

One first main, and maybe trivial, variable that may influence individuals' distress is the direct exposure to COVID-19. It is reasonable to assume that the more individuals were exposed to a physical threat, the more they perceived high health risk for themselves and significant others (Cava et al., 2005) and, in turn, the more they experience distress. Some research found that COVID-19 direct exposure (Pirutinsky et al., 2020) or living close to positive cases (Di Giuseppe et al., 2020) are associated with higher distress. However, other variables may play a role in this relationship. Hawryluck et al. (2004) showed that acquaintance with or direct exposure to someone with SARS diagnosis was associated with a worrying condition. Worry is a cognitive coping response that serves as an avoidant function to respond to the immediate distress associated with a threat or something that could be perceived as potentially overwhelming and dangerous (Borkovec et al., 2004). However, paradoxically this strategy on a long term may lead to increased distress (Hayes et al., 1996), anxiety, and mood disorders (Beck et al., 2001).
Furthermore, there is evidence that, during outbreaks of epidemic or pandemic proportions, people require immediate health information (Gudykunst \& Nishida, 2001; Hyvärinen $\&$ Vos, 2016). When experiencing fear, people are pushed toward seeking information as a coping strategy (Allen et al., 2014; Lin et al., 2014; Salvi et al., 2021), given that search can help mitigate the feelings of uncertainty that generally spread during a time of threat (Kossowska \& Bukowski, 2015). Coping strategies refers to psychological patterns of thoughts and actions that individuals use to deal with aversive situations (Carver et al., 1989; Holahan \& Moos, 1987; Wechsler, 1995). For example, immediately following the announcement of the H1N1 outbreak, people increased their health-information seeking behaviors on websites (Tausczik et al., 2012). Even though information seeking behavior is one of the possible coping strategy to deal with uncertainty (Rosen et al., 2007; Rosen \& Knäuper, 2009), it may result in an increased level of distress (Gualano et al., 2020; Rosen et al., 2007), especially when the information gathered is inconsistent (Brooks et al., 2020; Cava et al., 2005). Finally, research suggests that the willingness to adhere to the quarantine and lockdown measures is more prominent in individuals perceiving the threat as more dangerous (Dryhurst et al., 2020) and among those who have pronounced prosocial traits (Pfattheicher et al., 2020). As a result of this association, those individuals might also experience a better adaptation to the measures of restriction of freedom and better mental health (Grignoli et al., 2021; Petrocchi et al., 2021). Therefore, following the above mentioned considerations, we conjectured that:

Exposure to the COVID-19 increases distress directly (HP1a) and indirectly through the mediation of higher perception of worry (HP1b), greater health-related information seeking (HP1c), and better perception of the utility of the lockdown as a measure to decrease the COVID-19 spread (HP1d).

\section{The Effect of Intolerance of Ambiguity on Distress}

Besides contingent and external factors, such as the exposure to COVID-19, other factors might influence individuals' level of distress during pandemic, such as individual differences in personality (Mazza et al., 2020; Morelli et al., 2020), dispositions (Conversano et al., 2020; Rossi et al., 2020; Sebri et al., 2021), and coping strategies (Prout et al., 2020). Literature indicates that individual differences in the ability to tolerate ambiguous situations (e.g. situations that "cannot be adequately structured or categorized by an individual because of the lack of sufficient cues"; Budner, 1962, p.30) might influence the level of distress perceived by individuals. Specifically, when faced with unclear and unstructured situations, individuals with low tolerance for ambiguity perceive them as a 
source of discomfort and threat and this tendency to react negatively to ambiguity and uncertainty is likely to lead to increased level of distress (Budner, 1962; Furnham \& Ribchester, 1995; Iannello et al., 2017, 2021; Mac Donald, 1970; McLain, 1993), anxiety (Bardi et al., 2009), and worry (Buhr \& Dugas, 2006). Furthermore, high levels of worry among ambiguity intolerant people are also associated with the lack of perceived control over the situation (Endler et al., 2000). Individuals characterized by low tolerance for ambiguity might decide to behave in a way that they consider to be protective, such as seek for health information, as a strategy to reduce the level of uncertainty due to COVID-19 pandemic, and adhere to the lockdown restriction as a protective way to respond to the spread of the COVID-19 outbreak.

Therefore, in a context of profound uncertainty and ambiguity, like the COVID-19 pandemic outbreak, where future conditions are largely unpredictable and consistent information are mostly lacking, we expected that:

Higher levels of ambiguity intolerance correspond to higher distress directly and through the mediation of higher perception of worry (HP2b), greater health information seeking behaviors (HP2c), as a way to overcome uncertaintyinduced discomfort, and higher perceived utility of the lockdown as a measure of control of the pandemic (HP2d).

\section{The Relationship between Health Risk Aversion and Distress}

Literature highlights the existence of a relationship between intolerance for ambiguity and risk-taking propensity (Caligiuri \& Tarique, 2012). Individuals' reactions to risk and ambiguity tend to be consistent (Lauriola et al., 2007). As well as for the ambiguity intolerance, there appears to be an association between the perception of risk and the tendency to worry. Risk attitude has been defined as a dispositional trait or characteristic that reflects a "person standing on the continuum from risk aversion to risk seeking" (Weber et al., 2002: p. 264). Literature found that greater risk-aversion is generally associated to the tendency to worry and anxiety (Lorian \& Grisham, 2011; Maner \& Schmidt, 2006). The tendency to overestimate the probability and severity of negative outcomes could possibly contribute to explain the relationship between negative risk orientation and worry (Koerner et al., 2017). Furthermore, risk attitude has been found to be a motivator for information-seeking behaviors (Griffin et al., 2004; Riva et al., 2015; Turner et al., 2006) and a predictor of selfprotective actions (Janz \& Becker, 1984). Perceiving a heightened likelihood of aversive events may possibly push riskavert people to seek out information and take preventive action to control the situation, especially during an emergency, like COVID-19 pandemic. Therefore, we expected that:
Risk aversion positively influences individuals' distress directly (HP3a) and indirectly through the increasing of worry (HP3b), greater health-related information seeking behavior (HP3c), and more positive perception of the utility of the lockdown as useful way to keep the spread of the COVID-19 under control (HP3d).

\section{The Hypothesized Model of Relationships}

The hypothesized associations among constructs are summarized in a theoretical model shown in Fig. 1. Given that women experience higher distress than men (Papini et al., 1990), gender has been tested as a covariate.

\section{Method}

\section{Participants}

The study was conducted in Italy during March-April 2020 using a snowball sampling method by posting the link to the survey on several public and private Facebook pages. The survey was implemented on Qualtrics ${ }^{\mathrm{XM}}$ software. Inclusion criteria were: (i) age 18+; (ii) fluency in Italian; (iii) being resident in Italy. Health-related workers (physicians, nurses, psychiatrists, psychologists, and psychotherapists) were excluded from the sample because they were not forced to respect the lockdown. An a-priori power analysis applying G*Power 3.1.9.4 (Faul et al., 2007) was conducted to determine the sample size ( with $\alpha$-level $=.05$, power $=.95, \eta^{2}=$ 0.07 ) and the final estimate was 224 participants.

Participants were 240 adults from 18 to 76 years of age $(\mathrm{M}=39.67, \mathrm{SD}=15.2 ; 79$ males $)$. Most of them were employed (55\%), 37\% were not employed, and $8 \%$ were retired. One hundred eighty-six participants declared to be in a stable relationship (78\%), whereas the $8 \%$ lived alone at the time of the data collection ( $92 \%$ lived with at least one family member). Table 1 shows sociodemographic characteristics of respondents.

\section{Measures}

A self-administered questionnaire was created to assess sociodemographic characteristics in order to collect data on gender, age, employment, relationship status, and cohabitants.

COVID-19 Exposure Participants were asked to indicate if they were tested positive or they experienced symptoms related to the COVID-19. Similarly, they were asked whether their partner(s), relatives or friends were tested positive or had had compatible symptoms, and if someone who was close to them died for COVID-19 (Li et al., 2020; Petrocchi et al., 2020). 
Fig. 1 Theoretical model tested

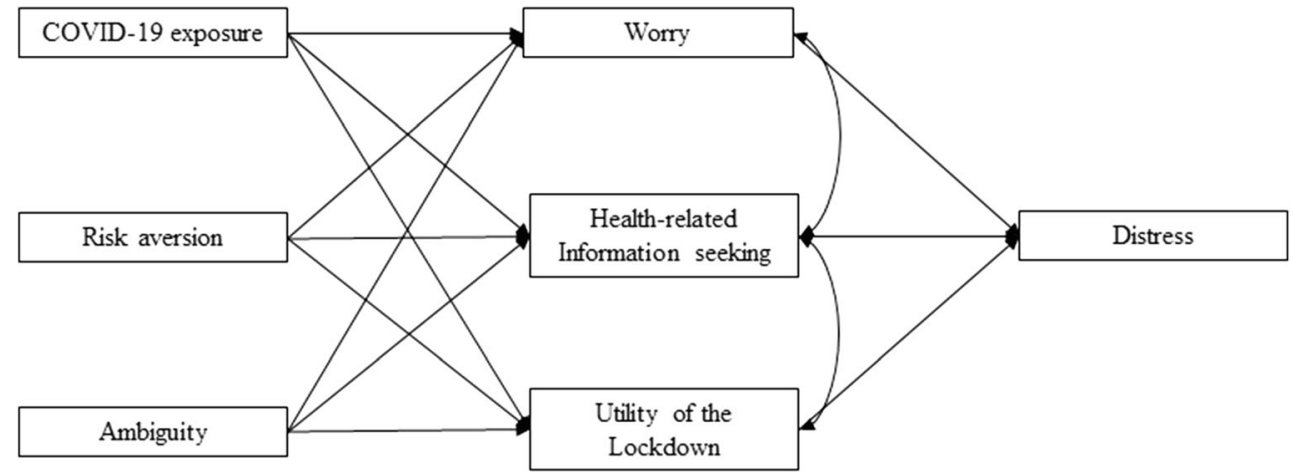

Two sample items were "Have you tested positive for COVID-19?" and "Has your partner tested positive for COVID-19?". Response options were dichotomous and a final score was computed as a sum. The higher the final score, the higher the number of exposures of the participant to COVID-19 infection, to people infected, or with compatible symptoms with COVID-19. This variable ranged from 0 to 5 .

Worry Participants were asked to indicate their worry about contracting COVID-19 infection by themselves, family members, and significant others with 3 items as done in other studies (Sebri et al., 2021). Response options were on a 5point scale (ranging from "strongly disagree" to "strongly agree"). The items were: "I feel worried that I may be infected with COVID-19", "I feel worried that my family members may be infected with COVID-19" and "I feel worried that close contact of me may be infected with COVID-19. The higher the final score is, the higher worries about COVID-19 infection are. In this study, this scale has been shown to be internally consistent $(\alpha=.82, \mathrm{rs}>.51)$.

Table 1 Sociodemographic characteristics of respondents

\begin{tabular}{lll}
\hline & Total sample $(N=240)$ & \\
\cline { 2 - 3 } & $n$ & \\
\hline Gender & 161 & 67 \\
Female & 79 & 33 \\
Male & & \\
Employment & 91 & 37 \\
Unemployed & 6 & 55 \\
Employed & 73 & 8 \\
Retired & & \\
Relational status & 187 & 78 \\
In a relationship & 53 & 22 \\
Single & & 8 \\
Cohabitants & 19 & 92 \\
Alone & 221 & \\
One or more & & \\
\hline
\end{tabular}

Health-Related Information Seeking The frequency with which participants searched medical information through physicians during COVID-19 lockdown was investigated with a single item developed ad-hoc ("During COVID-19 lockdown, how often do you search medical information through physicians?"). A 5-point Likert scale ranging from "never" to "ever" was used, with higher scores indicating higher tendency to seek for information.

Utility of the Lockdown Participants were asked to indicate their perceived utility of the lockdown to stop spreading COVID-19. It was evaluated with 3 items, developed ad-hoc (Grignoli et al., 2021; Petrocchi et al., 2021), with response options on a 5-point scale ranging from "strongly false" to "strongly true". The items were: "Lockdown is not very effective to stop the spread of COVID-19", "So many people are affected by COVID-19 that lockdown is useless", and "COVID-19 is not very contagious, so lockdown is useless". The items were reverse coded. The higher the total score is, the higher the perception of usefulness of the lockdown as a measure of outbreak containment is. The internal consistency of the scale was moderate $(\alpha=.70, \mathrm{rs}>.43)$.

Risk Aversion This construct was measured with the Health Risk Attitude Scale (HRA-6; Dieteren et al., 2020), a selfreport scale (6 items), validated for Dutch people and back translated into Italian, that assesses how a person would resolve risky health decisions and includes questions related to risky and preventive health behavior and related to medical treatment. Ranging from "completely disagree" to "completely agree", the 5-point Likert scale is used to measure the individual health risk attitude. It has been calculated a total score with higher scores indicating stronger risk-averse attitudes. In this study, the scale has been shown to be internally consistent (Cronbach $\alpha=.79$, rs $>.17$, CFA results $\chi^{2}(9)=30.85$, $p<.001, \mathrm{CFI}=.96, \mathrm{RMSEA}=.10)$.

Intolerance for Ambiguity The construct was measured with the ambiguity scale of the Need for Closure questionnaire, a validated questionnaire for Italian adults (Pierro et al., 1995). The intolerance for ambiguity, which is measured through 7 
items, is defined as a desire for any type of answer in order to end further information processing, rather than remaining in doubt and ambiguity. Response options varied from 1 ("strongly disagree") to 4 ("agree"). Cronbach's alpha coefficients was equal to .68 for the total scale (with the exclusion of item 7; rs $>.31$; CFA results $\chi^{2}(14)=44.49, p<.001$, $\mathrm{CFI}=.85, \mathrm{RSMEA}=.09$ ).

Distress about COVID-19 Outbreak Emotional distress related to COVID-19 was investigated asking participants how often, during the previous two weeks, they feel eight specific emotional reactions when thinking about COVID-19 outbreak (calm, tense, upset, relaxed, concerned, uninvolved, content, and active). Response was on a 4 - point Likert scale. All participants evaluated all the 8 emotional reactions referred to the COVID-19 pandemic. Those items were created adhoc for the present investigation, however similar questions were asked in another study on adults during COVID-19 (Grignoli et al., 2021; Petrocchi et al., 2021). Reverse score was applied to the positive emotions and a total score was calculated as average. The higher the total score is, the higher the distress related to COVID-19 outbreak is. In this study, the scale showed a Cronbach's alpha coefficients equal to .80 (rs $>.25$; CFA results $\chi 2(14)=61.34, p<.001, \mathrm{CFI}=90$, RSMEA $=.10)$.

\section{Procedure}

Data collection was conducted via snowball sampling. The survey was spread through a Qualtrics link. The only inclusion criterion was having 18 years or above. Exclusion criterion was working as health-care professionals in order to keep under control the individual's level of engagement in COVID-19 management. Participants completed an informed consent before starting the survey and did not receive any compensation. Ethical Approval was obtained from the university's Ethical Committee (N. 19,133).

\section{Data Analysis Strategy}

Data analyses were performed using the statistical software analysis package SPSS (Version 26.0) and AMOS v. 24. Data were normally distributed. Independent samples t-tests were performed to identify systematic differences in the distribution of gender in the variables. Correlations were computed to test the association between variables.

For the main analyses, the hypothesized model (Fig. 1) was tested using structural equation modelling (SEM). All the socio-demo variables were entered as control variables. The following goodness-of-fit indices were used to evaluate model-data correspondence: $\chi^{2}$ value, $\chi^{2} /$ df ratio, Comparative Fit Index (CFI), and Root Mean Square Error of Approximation (RMSEA). Given the $\chi^{2}$ value is influenced by the sample size, Byrne (2016) suggested to accept a model when the CFI is higher than .90 and close to .95 and the RMSEA is .08 or less. Bootstrapping method was also applied. Finally, modifications indices and the matrix of standardized correlation residuals were inspected for potential improvement of model fit. The reverse model was tested and compared to the main model via $\Delta \chi^{2}$.

\section{Results}

\section{Preliminary Analyses}

T-tests showed a significant difference between males and females regarding the mean scores in the perceived usefulness of the lockdown $(\mathrm{t}(113.567)=-2.130, p=.035)$. Specifically, women perceived the lockdown more useful $(\mathrm{M}=4.36$; $\mathrm{SD}=$ $0.669)$ than that perceived by men $(M=4.10 ; \mathrm{SD}=0.888)$. Women also showed, on average, higher levels of distress $(\mathrm{M}=2.99, \mathrm{SD}=0.41)$ than those manifested by men $(\mathrm{M}=$ 2.75; $\mathrm{SD}=0.50)$. This difference was significant $(\mathrm{t}$ $(131.321)=-3.704, p<.001)$. No other statistically significant gender differences were found in the dimensions belonging to the model presented.

Significant associations emerged between gender, utility of the lockdown, and distress. Age correlated with utility of the lockdown. Cohabitants with COVID-19 exposure, which, in turn, correlated with worry and health-related information seeking. Risk aversion correlated with utility of the lockdown. Ambiguity intolerance correlated with distress, which was correlated with worry, health-related information seeking, and utility of the lockdown. Table 2 shows means, standard deviations, and correlations between variables.

\section{Primary Analyses Testing the Hypothesized Model}

The hypothesized model was tested with the distress on the total sample $(n=240)$. Initially, all the socio-demo covariates were entered in the model. The fit indices showed a low fit with the data, $\chi^{2}(38)=89.12, \chi^{2} / \mathrm{df}=2.34, p=.56, \mathrm{CFI}=.82$, and RMSEA $=.11,90 \%$ CI [.049 .17]. Only gender was significant, therefore a second model was tested with gender as a control variable. The final model (Fig. 2) showed good fit of the data with $\chi^{2}(17)=15.48, \chi^{2} / \mathrm{df}=0.91, \mathrm{p}=.56, \mathrm{CFI}=1$, and RMSEA $=.00,90 \%$ CI [.000 .054]. Since intolerance of ambiguity and distress were measured on a 4-point Likert scale, we tested two alternative models. First we created two dummy variables, one for intolerance of ambiguity and one for distress, considering the $50 \%$ percentile as a cut-off point and we re-tested the model. The model showed a good fit of the data with $\chi^{2}(11)=31.68, \chi^{2} / \mathrm{df}=2.88, p=.001$, $\mathrm{CFI}=.95$, and RMSEA $=.09$, 90\% CI [.057 .13]. Second, we tested the same model with intolerance of ambiguity and 
Table 2 Means, standard deviations, and correlations between main variables and control variables

\begin{tabular}{|c|c|c|c|c|c|c|c|c|c|c|}
\hline & $\mathrm{M}(\mathrm{SD})$ & (1) & $(2)$ & (3) & (4) & (5) & (6) & (7) & (8) & (9) \\
\hline Gender $^{1}$ & - & $-.27 * * *$ & .05 & -.01 & -.09 & .10 & .05 & -.02 & $.16^{*}$ & $.26^{* * *}$ \\
\hline Age (1) & $36.67(15.21)$ & & -.09 & .07 & .11 & .07 & .02 & .09 & $-.16^{*}$ & -.04 \\
\hline Cohabitants (2) & $2.49(1.41)$ & & & $-.16^{*}$ & $.21 * *$ & .03 & -.07 & -.01 & -.13 & -.09 \\
\hline COVID-19 exposure (3) & $.97(1.04)$ & & & & .05 & .02 & $.23 * * *$ & $.19 * * *$ & .03 & .03 \\
\hline Risk Aversion (4) & $3.8(.64)$ & & & & & .01 & .07 & $.21 * *$ & $.29 * * *$ & -.05 \\
\hline Intolerance for ambiguity ${ }^{2}(5)$ & $3.14(.40)$ & & & & & & .07 & .04 & -.05 & $.34 * * *$ \\
\hline Worry (6) & $3.67(.89)$ & & & & & & & $.20 * *$ & -.05 & $.34 * * *$ \\
\hline Health-related information seeking behavior (7) & $1.92(1)$ & & & & & & & & $.20 * *$ & $.15^{*}$ \\
\hline Utility of the lockdown (8) & $4.27(.75)$ & & & & & & & & & $.22 * *$ \\
\hline $\operatorname{Distress}^{2}(9)$ & $3.08(.39)$ & & & & & & & & & \\
\hline
\end{tabular}

$* p<.05 ; * *<.01 ; * * * p<.001$; correlation coefficients are Pearson's $r$ except for ${ }^{1}$ Kendall's tau-b and ${ }^{2}$ Spearman's Rho.

distress (non dummy coded) applying WLSMV estimator for ordinal data. The model showed a good fit of the data with $\chi^{2}$ $(14)=30.94, \chi^{2} / \mathrm{df}=2.21, p=.006, \mathrm{CFI}=.93$, and RMSEA $=.07,90 \%$ CI [.039 .11]. The resulting paths of the two alternative models were similar to the estimated final model. Therefore we decided to report results of the first model tested.

Worry was significantly related to distress $(\beta=.31$, $\mathrm{SE}=.039, \mathrm{CI}[.13 .37], p<.001)$, indicating that increased worry for COVID-19 led to higher levels of distress during quarantine. Likewise, the utility of the quarantine was significantly negatively related to distress $(\beta=-.24, \mathrm{SE}=.054$, $\mathrm{CI}[.07 .28], \mathrm{p}<.001)$. Information seeking behavior was significantly related to distress $(\beta=.13, \mathrm{p}=\mathrm{SE}=.039, \mathrm{CI}[.02$ $.15], p=.033$ ), that is the more an individual asks for information to a doctor during the quarantine, the more he/she experiences distress. Furthermore, information seeking behavior and utility of the quarantine were correlated with each other $(\beta=.15, \mathrm{SE}=.044, \mathrm{CI}[.04 .18], p=.025)$. Among the predictors, COVID-19 exposure was significantly related to worry $(\beta=.23, \mathrm{SE}=.039, \mathrm{CI}[.03 .33], p<.001)$ and information seeking behavior $(\beta=.18, \mathrm{SE}=.066, \mathrm{CI}[.16 .25]$, $p=.006$ ), whereas risk aversion was significantly related to information seeking behavior $(\beta=.20, \mathrm{SE}=.066, \mathrm{CI}[.11 .27]$, $p=.003)$ and utility of the quarantine $(\beta=.29, \mathrm{SE}=.11$, $\mathrm{CI}[.10 .34], p<.001)$. Intolerance of the ambiguity was significantly and directly related with distress $(\beta=.12, \mathrm{SE}=.10$, CI[.11 .27], $\mathrm{p}<.001)$.

Moreover, the indirect paths from COVID-19 exposure to distress were significant both through worry $(\beta=.03$, $\mathrm{SE}=.008, \mathrm{CI}[.007 .015], p<.001)$ and health-related information seeking $(\beta=.011, \mathrm{SE}=.004, \mathrm{CI}[.007 .012]$, $p=.008$ ), whereas the indirect paths from risk aversion to distress through health-related information seeking and utility of the lockdown were not significant. The total effect from COVID-19 exposure to distress and from risk aversion to distress were not significant. Additionally, gender was significantly related to distress $(\beta=.21, \mathrm{SE}=.07, \mathrm{CI}[.024 .31]$, $p<.001)$ with females more stressed than males.

Since the present study has a cross-sectional design, the reverse model (i.e., testing the same pattern of relationships among variables but with reverse directions) was also tested reaching a significant $\left.\chi^{2}(21)=42.34, p=.004\right)$, and worse $\mathrm{CFI}=.78, \mathrm{RMSEA}=.065$ compared to the previous model. $\Delta \chi^{2}(4)=26.86, p<.001, \Delta \mathrm{CFI}$ and $\Delta \mathrm{RMSEA}=.065$ indicate that the first model better fit the data.
Fig. 2 Results of the tested model. Dot lines indicate nonsignificant paths; plain lines indicate significant paths

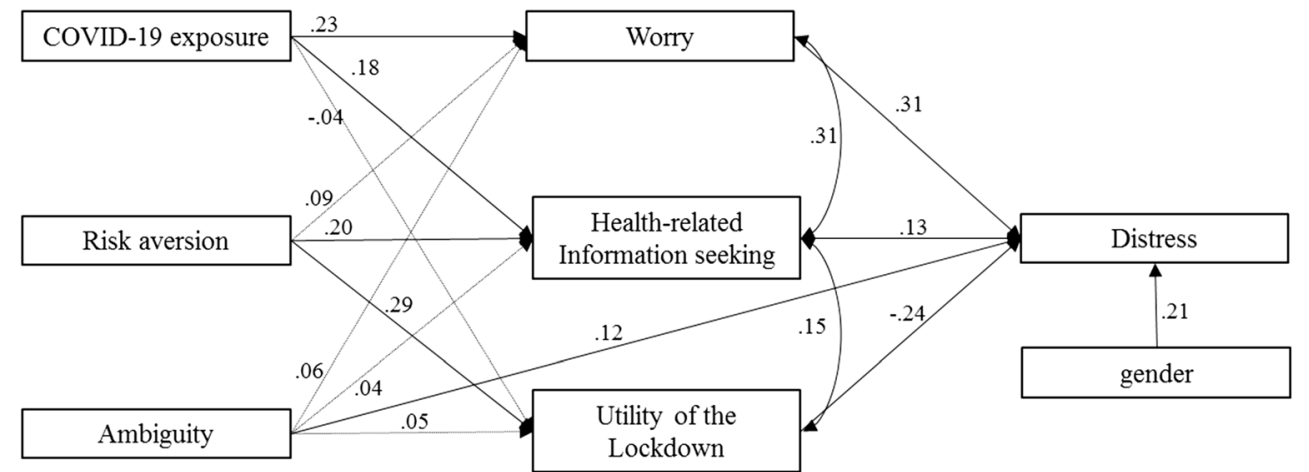




\section{Discussion}

The non-pharmaceutical measures implemented during the COVID-19 pandemic, such as the lockdown of the population and quarantine of positive cases, have been found to be effective in reducing quickly the spread of the virus (NussbaumerStreit et al., 2020). However, lockdown is often an unpleasant experience for those who undergo it. Separation from loved ones, loss of freedom, uncertainty over disease status and the duration of the lockdown itself, burden for financial and economic consequences, and boredom can, on occasion, create dramatic effects (Brooks et al., 2020; Hossain et al., 2020). The eventuality of a second wave of COVID-19 was already hypothesized in April 2020 (Leung et al., 2020), and then many hotspots were confirmed, for example, in Italy, China, and Germany in the subsequent months. Massive efforts have been applied by public health interventions nationwide to contain the outbreak. However, psychological supportive interventions are particularly needed to help people to cope with the situation (Dominguez-Salas et al., 2020; Lei et al., 2020). The present study aimed at examining several mechanisms responsible for high levels of distress and then to identify possible mechanisms to be considered in supportive interventions. Particularly, we studied the impact of two individual features, risk aversion and intolerance of ambiguity, together with COVID-19 exposure, on distress measured during the mandatory lockdown in Italy. These relations were tested through the moderation of worry, health-related information seeking behavior, and perception of the utility of the lockdown.

Literature supports the notion that being directly exposed to COVID-19 threat is associated with physical symptoms, stress, and anxiety (Chew et al., 2020; Wang et al., 2020). The exposition of a serious threat for physical safety enhances the perception of health risk for themselves and for significant others (Cava et al., 2005) and, consequently, distress. In line with such considerations, our findings suggests that COVID19 exposure increased the worry perception (Sebri et al., 2021) which, in turn, was associated with higher distress. This result is consistent with the literature (Gudykunst \& Nishida, 2001), which identifies high uncertainty as a risk factor for the development of negative psychological mental health. The COVID-19 exposure brings people in direct contact with high levels of uncertainty, due to possible serious medical complications and lack of effective and specific treatments for the virus. Similarly, the COVID-19 exposure enhances health-related information seeking as a way to limit the uncertainty due to the pandemic, and this leads to greater distress for reasons that we explore just below.

Beside COVID-19 exposure, our results suggested that individual characteristics exert an effect on the individual psychological well-being. Risk aversion determined greater health-related information seeking and perception of utility of the lockdown, which were significantly related to distress with a positive and negative sign, respectively. Therefore, our results provide an articulated picture. It seems that risk aversion represents a risk factor, when stimulates health information seeking because, in an uncertain situation characterized by an informative overload (Reich et al., 2006), the search for information leads to a worse psychological functioning. Even though information seeking behavior is one of the possible response to uncertainty (Rosen et al., 2007; Rosen \& Knäuper, 2009), it may also result in an increased level of distress (Reich et al., 2006), depending on the specific content of the information (Rosen et al., 2007). This aspect was also explained by Cava et al. (2005) during the SARS outbreak, when many participants reported that inconsistent information from various sources led them to question the reliability of available information. Moreover, as shown by DominguezSalas et al. (2020), when adequate information is lacking, people double their efforts to fill the informative gap, sometimes choosing non-reliable sources such as social media and internet (Abd-Alrazaq et al., 2020; Cuan-Baltazar et al., 2020; Zhao et al., 2020) and contributing to create an overload. Hence, during the COVID-19 lockdown, a condition in itself characterized by profound uncertainty, incomplete and inconsistent information, even if received by physicians, together with an informative overload may have casted doubt on the reliability of information and on the trust placed in the health professionals, generating consequently higher levels of distress.

On the other hand, risk aversion acted as a protective factor increasing the perception of utility of the lockdown. When individuals think that the lockdown is effective in reducing the spread of the pandemic, although interrupts the normal daily functioning and has a detrimental effect on psychological adaptation (Brooks et al., 2020), they might be able to adapt themselves to the mandatory situation leading to a lower distress.

Contrary to the expectations, worry did not mediate the relationship between risk aversion and distress. This result may probably be related to the specific scale used in the present study to measure the construct of worry. Literature reports an association between risk aversion and worry, mainly referred to trait, generalized excessive worry (Lorian \& Grisham, 2011). Our items specifically measured the level of worry that people perceived in responses to COVID-19 outbreak because that was the focus of our investigation. This may have reduced the strength of the association.

Finally, intolerance for ambiguity was found to be directly associated with distress, which was higher in females than males. Therefore, it seems that the higher the ability to tolerate ambiguity, the less the emotional distress experienced, in a specific situation where uncertainty and unpredictability dominate, as during the lockdown due to COVID outbreak. Anyway, the relationships between low tolerance for 
ambiguity and decision-making are not linear. Intolerance for ambiguity may generate behaviors aimed to reduce the level of uncertainty even if, on a long time basis, such behaviors might not be adaptive or appropriate anymore and might enhance a negative emotional experience (Han et al., 2006, 2007). Ambiguity aversion thus leads to an alarmistic response, a pessimistic bias (Viscusi, 1997) defined as the tendency to reserve an excessive amount of attention and effort to the worst scenario possible in case of ambiguous risk information. The pessimistic bias has been proved to be persistent over time even when the situation is less far than ambiguous (Curley \& Yates, 1985; Keren \& Gerritsen, 1999) and able to provoke a sequela of psychological symptoms.

Worry, health-related information seeking, and perceived utility of the lockdown did not mediate the relation between low tolerance for ambiguity and distress. As for worry, an association was expected since the literature found that trait worry increases in individuals with low levels of tolerance of ambiguity (Buhr \& Dugas, 2006). In our study, as mentioned before, we measured a state worry dimension specifically referred to the COVID-19 spread, and this might have deflated the expected association, as for risk aversion.

As for health-related information seeking behavior, we expected to find a relationship between high levels of ambiguity intolerance and the tendency to seek out information (Litman, 2010), as a way to get greater control over the situation. However, it has to be taken into consideration the peculiarity of the COVID-19 situation, defined as "infodemic" (WHO, W. H. O, 2020), thus referring to the overabundance of information, often inconsistent, fragmented, incomplete, and not accurate. High ambiguity intolerant people, who generally find it difficult to manage contradictions and incomplete information (Chiang, 2016), may have experienced a sense of confusion and overload that have prevented them from seeking out for further information. It might be that high ambiguity intolerant people, when overwhelmed by numerous and incoherent information, struggle to integrate them in a coherent picture and then they tend to avoid searching for other information. Finally, high ambiguity aversion, combined with the amount of information received by individuals, might have decreased trust toward institutions and, by extension, toward the restrictive measures they imposed (e.g., lockdown).

\section{Limitations}

The present study has several limitations. First, the most part of our participants (or their partner, family members, friends) were not directly exposed to COVID-19. Although the status reflects the situation of the majority of the people under the lockdown due to COVID-19 pandemic, it could be expected to have different paths of relations among variables if COVID-19 positive individuals would have been interviewed.
For many evident practical and ethical reasons a data collection on COVID-19 positive individuals would be possible only retrospectively. A second limitation of the study concerns the sample size. Although the a-priori power analysis demonstrated that a sample of 224 participants would be enough to detect the expected effects, we realize that the size of the sample may inflate the generalizability of the results. Another limitation concerns the measures applied in the study. All the measures we utilized are self-reported and the distress items have been created ad hoc for the study. We realize that this might have created a bias in the results. However, during the lockdown period it was impossible to conduct data collection via non-self-reported measures and, given the urgency of the investigation, we chose for the faster and quicker way possible. Finally, we treated the ambiguity of intolerance in the context of need of closure using the discomfort with ambiguity subscale of the Need for Closure questionnaire. Even if that subscale correlates with other questionnaires measuring ambiguity intolerance (e.g. Webster \& Kruglanski, 1994), we should be cautious in generalizing results. Third, we did not differentiate among different sources of stress. We asked participants to think about the previous weeks when replying to the questions regarding the emotional experience. However, it might be that the source of the distress would come from events other than the COVID-19 pandemic but related to it, such as difficulties in balancing smart working and family responsibilities, financial loss, or the risk of losing the job.

\section{Conclusion}

Our research highlights the role played by several factors in moderating the levels of distress during an extremely challenging situation, such as the one people experiment during a pandemic and a subsequent lockdown period. Our evidence suggests the presence of differential paths between risk aversion and distress and between intolerance for ambiguity and distress. Risk aversion represents, at the same time, a risk and a protective factor, based on what variable mediates its relationship with distress. This evidence suggests that risk aversion might have a differential effect on individuals' decisionmaking and behaviors, and then on distress. On the other hand, the intolerance for ambiguity is directly linked to distress and thus represents a risk factor for mental health. Taken together this evidence leads to some considerations regarding the possible interventions sustaining individuals' mental health and the principles guiding communication in times of crisis.

Supporting individuals' psychological adjustment under the urgency of a pandemic is quite challenging, but several attempts are ongoing (Bashshur et al., 2020; Bäuerle et al., 2020). The interventions aiming to diminish distress by reducing the negative effect of risk factors and activating protective 
factors (Bäuerle et al., 2020) may find new support on our results. Our findings support the evidence that individuals' variables, together with COVID-19 exposure, play a role on mental health during a pandemic outbreak.

Furthermore, balanced communication during a health crisis is complex (Brivio et al., 2020), nowadays even more with social media and internet often provoking with shocking or even false information. For the particular case of the COVID19, communication has involved many channels (e.g., newscasts, trash TV programs, social media, internet), with different levels of competence and credibility. Our results suggest that pushing on the button of fear and uncertainty may lead to inconsistent outcomes and often have a boomerang effect (Witte, 1992), due to the fact that low tolerance for ambiguity and greater worry lead to high distress and those aspects makes people less willing to adopt protective behaviors (Ritov \& Baron, 1990; Viscusi, 1997; Viscusi et al., 1991). Moreover, during a pandemic the flow of information has to be controlled in its quantity, not only in its quality, because individuals with high risk aversion tendency are more prone to look for information and this behavior tends to enhance their distress.

Acknowledgments This work was partially supported by the Italian Ministry of Health with Ricerca Corrente and 5x1000 funds. G.O. is a PhD student within the European School of Molecular Medicine (SEMM).

Authors' Contribution SP and PI conceptualized the ideas, formulated the research goals and hypotheses, and collected data. SP and GO performed the analyses. AA and GP supervised the research. SP, PI, and GO wrote the manuscript and all the authors provided feedback and approved the final version of the paper.

Funding No funding was received.

Availability of Data and Material The data that support the findings of this study are available from the corresponding author, upon reasonable request.

Code Availability Not applicable.

\section{Declarations}

Conflicts of Interest/Competing Interests The authors declare that they have no competing interests.

\section{References}

Abd-Alrazaq, A., Alhuwail, D., Househ, M., Hai, M., \& Shah, Z. (2020). Top concerns of tweeters during the COVID-19 pandemic: A surve study. Journal of Medical Internet Research., 22, e19016. https:// doi.org/10.2196/19016.

Ahmed, M, Z., Ahmed, O., Aibao, Z., Hanbin, S., Siyu, L., \& Ahmad, A. (2020). Epidemic of COVID-19 in China and associated psychological problems. Asian Journal of Psychiatry, 51. https:// doi.org/10.1016/j.ajp.2020.102092.

Allen, D. K., Karanasios, S., \& Norman, A. (2014). Information sharing and interoperability: The case of major incident management. European Journal of Information Systems., 23, 418-432. https:// doi.org/10.1057/ejis.2013.8.

Arvidsdotter, T., Marklund, B., Kylén, S., Taft, C., \& Ekman, I. (2016). Understanding persons with psychological distress in primary health care. Scandinavian Journal of Caring Sciences., 30, 687-694. https://doi.org/10.1111/scs.12289.

Bardi, A., Guerra, V. M., \& Ramdeny, G. S. D. (2009). Openness and ambiguity intolerance: Their differential relations to well-being in the context of an academic life transition. Personality and Individual Differences., 47, 219-223. https://doi.org/10.1016/j.paid.2009.03. 003.

Bashshur, R., Doarn, C. R., Frenk, J. M., Kvedar, J. C., \& Woolliscroft, J. O. (2020). Telemedicine and the COVID-19 pandemic, lessons for the future. Telemedicine and e-Health., 26, 571-573. https://doi.org/ 10.1089/tmj.2020.29040.rb.

Bäuerle, A., Graf, J., Jansen, C., Dörrie, N., Junne, F., Teufel, M., \& Skoda, E.-M. (2020). An e-mental health intervention to support burdened people in times of the COVID-19 pandemic: CoPE it. Journal of Public Health., 42, 647-648. https://doi.org/10.1093/ pubmed/fdaa058.

Beck, R., Perkins, T. S., Holder, R., Robbins, M., Gray, M., \& Allison, S. H. (2001). The cognitive and emotional phenomenology of depression and anxiety: Are worry and hopelessness the cognitive correlates of NA and PA? Cognitive Therapy and Research., 25, 829838. https://doi.org/10.1023/A:1012983726272.

Bhattacharyya, M., Marston, L., Walters, K., D'Costa, G., King, M., \& Nazareth, I. (2014). Psychological distress, gender and dietary factors in south Asians: A cross-sectional survey. Public Health Nutrition, 17(7), 1538-1546. https://doi.org/10.1017/ S136898001300147X.

Borkovec, T. D., Alcaine, O. M., \& Behar, E. (2004). Avoidance \{theory $\}$ of $\{$ worry $\}$ and $\{$ generalized $\{$ anxiety\} \{disorder $\}$. In Generalized anxiety disorder: \{Advances\} in research and practice.

Brivio, E., Oliveri, S., \& Pravettoni, G. (2020). Empowering communication in emergency Contexts: Reflections From the Italian Coronavirus Outbreak. Mayo Clinic Proceedings. Elsevier Ltd. https://doi.org/10.1016/j.mayocp.2020.03.021.

Brooks, S. K., Webster, R. K., Smith, L. E., Woodland, L., Wessely, S., Greenberg, N., \& Rubin, G. J. (2020). The psychological impact of quarantine and how to reduce it: Rapid review of the evidence. The Lancet., 395, 912-920. https://doi.org/10.1016/S0140-6736(20) 30460-8.

Budner, S. (1962). Intolerance of ambiguity as a personality variable. Journal of Personality, 30, 29-50. https://doi.org/10.1111/j.14676494.1962.tb02303.x.

Buhr, K., \& Dugas, M. J. (2006). Investigating the construct validity of intolerance of uncertainty and its unique relationship with worry. Journal of Anxiety Disorders., 20, 222-236. https://doi.org/10. 1016/j.janxdis.2004.12.004

Byrne, B, M. (2016). Structural Equation Modeling With AMOS. Structural equation modeling with AMOS. https://doi.org/10.4324/ 9781410600219

Caligiuri, P., \& Tarique, I. (2012). Dynamic cross-cultural competencies and global leadership effectiveness. Journal of World Business., 47, 612-622. https://doi.org/10.1016/j.jwb.2012.01.014.

Carver, C. S., Scheier, M. F., \& Weintraub, K. J. (1989). Assessing coping strategies: A theoretically based approach. Journal of Personality and Social Psychology, 56(2), 267-283. https://doi. org/10.1037/0022-3514.56.2.267.

Cava, M. A., Fay, K. E., Beanlands, H. J., McCay, E. A., \& Wignall, R. (2005). Risk perception and compliance with quarantine during the 
SARS outbreak. Journal of Nursing Scholarship., 37, 343-347. https://doi.org/10.1111/j.1547-5069.2005.00059.x.

Chew, N. W. S., Lee, G. K. H., Tan, B. Y. Q., Jing, M., Goh, Y., Ngiam, N. J. H., Yeo, L. L. L., Ahmad, A., Ahmed Khan, F., Napolean Shanmugam, G., Sharma, A. K., Komalkumar, R. N., Meenakshi, P. V., Shah, K., Patel, B., Chan, B. P. L., Sunny, S., Chandra, B., Ong, J. J. Y., Paliwal, P. R., Wong, L. Y. H., Sagayanathan, R., Chen, J. T., Ying Ng, A. Y., Teoh, H. L., Tsivgoulis, G., Ho, C. S., Ho, R. C., \& Sharma, V. K. (2020). A multinational, multicentre study on the psychological outcomes and associated physical symptoms amongst healthcare workers during COVID-19 outbreak. Brain, Behavior, and Immunity., 88, 559-565. https://doi.org/10. 1016/j.bbi.2020.04.049.

Chiang, H.-H. (2016). A study of interactions among ambiguity tolerance, classroom work styles, and English proficiency. English Language Teaching., 9, 61. https://doi.org/10.5539/elt.v9n6p61.

Coffey, K. A., \& Hartman, M. (2008). Mechanisms of action in the inverse relationship between mindfulness and psychological distress. Complementary Health Practice Review., 13, 79-91. https:// doi.org/10.1177/1533210108316307.

Conversano, C., Di Giuseppe, M., Miccoli, M., Ciacchini, R., Gemignani, A., \& Orrù, G. (2020). Mindfulness, age and gender as protective factors against psychological distress during COVID-19 pandemic. Frontiers in Psychology, 11 https://doi.org/10.3389/fpsyg.2020. 01900.

Cuan-Baltazar, J. Y., Muñoz-Perez, M. J., Robledo-Vega, C., PérezZepeda, M. F., \& Soto-Vega, E. (2020). Misinformation of COVID-19 on the internet: Infodemiology study. JMIR Public Health and Surveillance., 6, e18444. https://doi.org/10.2196/18444.

Curley, S. P., \& Yates, J. F. (1985). The center and range of the probability interval as factors affecting ambiguity preferences. Organizational Behavior and Human Decision Processes., 36, 273-287. https://doi.org/10.1016/0749-5978(85)90016-0.

Di Giuseppe, M., Zilcha-Mano, S., Prout, T, A., Perry, J, C., Orrù, G., \& Conversano, C. (2020). Psychological impact of coronavirus disease 2019 among Italians during the first week of lockdown. Frontiers in Psychiatry, 11. https://doi.org/10.3389/fpsyt.2020.576597.

Dieteren, C. M., Brouwer, W. B. F., \& Van Exel, J. (2020). How do combinations of unhealthy behaviors relate to attitudinal factors and subjective health among the adult population in the Netherlands? BMC Public Health, 20, 441. https://doi.org/10. 1186/s12889-020-8429-y.

Dominguez-Salas, S., Gomez-Salgado, J., Andres-Villas, M., DiazMilanes, D., Romero-Martin, M., \& Ruiz-Frutos, C. (2020). Psycho-emotional approach to the psychological distress related to the COVID-19 pandemic in Spain: A cross-sectional observational study. Healthcare. https://doi.org/10.3390/healthcare8030190.

Dryhurst, S., Schneider, C. R., Kerr, J., Freeman, A. L. J., Recchia, G., van der Bles, A. M., Spiegelhalter, D., \& van der Linden, S. (2020). Risk perceptions of COVID-19 around the world. Journal of Risk Research., 23, 994-1006. https://doi.org/10.1080/13669877.2020. 1758193.

ECDC. (2020a). COVID-19 situation update worldwide, as of 9 July 2020. https://www.ecdc.europa.eu/en/geographicaldistribution-2019-ncov-cases

ECDC. (2020b). Download today's data on the geographic distribution of COVID-19 cases worldwide. https://www.ecdc.europa.eu/en/ publications-data/download-todays-data-geographic-distributioncovid-19-cases-worldwide

Endler, N. S., Macrodimitris, S. D., \& Kocovski, N. L. (2000). Depression: The complexity of self-report measures. Journal of Applied Biobehavioral Research. https://doi.org/10.1111/j.17519861.2000.tb00062.x, 5, 26, 46.

Faul, F., Erdfelder, E., Lang, A. G., \& Buchner, A. (2007). G*power 3: A flexible statistical power analysis program for the social, behavioral, and biomedical sciences. In Behavior Research Methods., 39, 175191. https://doi.org/10.3758/BF03193146.

Fernández, R. S., Crivelli, L., Guimet, N. M., Allegri, R. F., \& Pedreira, M. E. (2020). Psychological distress associated with COVID-19 quarantine: Latent profile analysis, outcome prediction and mediation analysis. Journal of Affective Disorders, 277, 75-84. https://doi. org/10.1016/j.jad.2020.07.133.

Furnham, A., \& Ribchester, T. (1995). Tolerance of ambiguity: A review of the concept, its measurement and applications. Current Psychology., 14, 179-199. https://doi.org/10.1007/BF02686907.

Griffin, R. J., Neuwirth, K., Dunwoody, S., \& Giese, J. (2004). Information sufficiency and risk communication. Media Psychology., 6, 23-61. https://doi.org/10.1207/ s1532785xmep0601 2.

Grignoli, N., Petrocchi, S., Bernardi, S., Massari, I., Traber, R., Malacrida, R., \& Gabutti, L. (2021). Influence of empathy disposition and risk perception on the psychological impact of lockdown during the coronavirus disease pandemic outbreak. Frontiers in Public Health. https://doi.org/10.3389/fpubh.2020.567337, 8.

Gualano, M. R., Lo Moro, G., Voglino, G., Bert, F., \& Siliquini, R. (2020). Effects of COVID-19 lockdown on mental health and sleep disturbances in Italy. International Journal of Environmental Research and Public Health, 17(13), 1-13. https://doi.org/10. 3390/ijerph17134779.

Gudykunst, W. B., \& Nishida, T. (2001). Anxiety, uncertainty, and perceived effectiveness of communication across relationships and cultures. International Journal of Intercultural Relations, 25, 55-71. https://doi.org/10.1016/S0147-1767(00)00042-0.

Han, P. K. J., Moser, R. P., \& Klein, W. M. P. (2006). Perceived ambiguity about cancer prevention recommendations: Relationship to perceptions of cancer preventability, risk, and worry. Journal of Health Communication., 11, 51-69. https://doi.org/10.1080/ 10810730600637541.

Han, P. K. J., Moser, R. P., \& Klein, W. M. P. (2007). Perceived ambiguity about cancer prevention recommendations: Associations with cancer-related perceptions and behaviours in a US population survey. Health Expectations., 10, 321-336. https://doi.org/10.1111/j. 1369-7625.2007.00456.x.

Harvey, D. M., \& Bray, J. H. (1991). Evaluation of an intergenerational theory of personal development: Family process determinants of psychological and health distress. Journal of Family Psychology, 4(3), 298-325. https://doi.org/10.1037/0893-3200.4.3.298.

Hawryluck, L., Gold, W. L., Robinson, S., Pogorski, S., Galea, S., \& Styra, R. (2004). SARS control and psychological effects of quarantine, Toronto, Canada. Emerging Infectious Diseases, 10, 1206 1212. https://doi.org/10.3201/eid1007.030703.

Hayes, S. C., Wilson, K. G., Gifford, E. V., Follette, V. M., \& Strosahl, K. (1996). Experiential avoidance and behavioral disorders: A functional dimensional approach to diagnosis and treatment. Journal of Consulting and Clinical Psychology., 64, 1152-1168. https://doi. org/10.1037/0022-006X.64.6.1152.

Holahan, C. J., \& Moos, R. H. (1987). Personal and contextual determinants of coping strategies. Journal of Personality and Social Psychology, 52(5), 946-955. https://doi.org/10.1037/0022-3514. 52.5.946.

Hossain, M, M., Sultana, A., \& Purohit, N. (2020). Mental health outcomes of quarantine and isolation for infection Prevention: A Systematic Umbrella Review of the Global Evidence. SSRN Electronic Journal. https://doi.org/10.2139/ssrn. 3561265.

Hyvärinen, J., \& Vos, M. (2016). Communication concerning disasters and Pandemics: Coproducing Community Resilience and Crisis Response. In The Handbook of International Crisis Communication Research. https://doi.org/10.1002/ 9781118516812.ch10. 
Iannello, P., Mottini, A., Tirelli, S., Riva, S., \& Antonietti, A. (2017). Ambiguity and uncertainty tolerance, need for cognition, and their association with stress. A study among Italian practicing physicians. Medical Education Online. https://doi.org/10.1080/10872981.2016. 1270009, 22.

Iannello, P., Sorgente, A., Lanz, M., \& Antonietti, A. (2021). Financial well-being as predictor of subjective and psychological well-being among emerging adults: Testing the moderator effect of individual differences. Journal of Happiness Studies, 22(3), 1385-1411. https://doi.org/10.1007/s10902-020-00277-x.

Janz, N. K., \& Becker, M. H. (1984). The health belief Model: A Decade Later. Health Education \& Behavior. https://doi.org/10.1177/ 109019818401100101

Keren, G., \& Gerritsen, L. E. M. (1999). On the robustness and possible accounts of ambiguity aversion. Acta Psychologica., 103, 149-172. https://doi.org/10.1016/s0001-6918(99)00034-7.

Koerner, N., Mejia, T., \& Kusec, A. (2017). What's in a name? Intolerance of uncertainty, other uncertainty-relevant constructs, and their differential relations to worry and generalized anxiety disorder*. Cognitive Behaviour Therapy, 46, 141-161. https://doi.org/ 10.1080/16506073.2016.1211172.

Kossowska, M., \& Bukowski, M. (2015). Motivated roots of conspiracies: The role of certainty and control motives in conspiracy thinking. In M. Bilewicz, A. Cichocka, \& W. Soral (Eds.), The psychology of conspiracy (p. 145-161). Routledge/Taylor \& Francis Group.

Lauriola, M., Levin, I. P., \& Hart, S. S. (2007). Common and distinct factors in decision making under ambiguity and risk: A psychometric study of individual differences. Organizational Behavior and Human Decision Processes., 104, 130-149. https://doi.org/10. 1016/j.obhdp.2007.04.001

Lei, L., Huang, X., Zhang, S., Yang, J., Yang, L., \& Xu, M. (2020). Comparison of prevalence and associated factors of anxiety and depression among people affected by versus people unaffected by quarantine during the COVID-19 epidemic in southwestern China. Medical Science Monitor. https://doi.org/10.12659/MSM.924609.

Leung, K., Wu, J. T., Liu, D., \& Leung, G. M. (2020). First-wave COVID-19 transmissibility and severity in China outside Hubei after control measures, and second-wave scenario planning: A modelling impact assessment. The Lancet., 395, 1382-1393. https://doi.org/10.1016/S0140-6736(20)30746-7.

Li, J. B., Yang, A., Dou, K., Wang, L. X., Zhang, M. C., \& Lin, X. Q. (2020). Chinese public's knowledge, perceived severity, and perceived controllability of COVID-19 and their associations with emotional and behavioural reactions, social participation, and precautionary behaviour: A national survey. BMC Public Health, 20(1), 1589. https://doi.org/10.1186/s12889-020-09695-1.

Lin, L., Savoia, E., Agboola, F., \& Viswanath, K. (2014). What have we learned about communication inequalities during the H1N1 pandemic: A systematic review of the literature. BMC Public Health https://doi.org/10.1186/1471-2458-14-484, 14.

Litman, J. A. (2010). Relationships between measures of I- and D-type curiosity, ambiguity tolerance, and need for closure: An initial test of the wanting-liking model of information-seeking. Personality and Individual Differences., 48, 397-402. https://doi.org/10.1016/j.paid. 2009.11.005.

Lorian, C. N., \& Grisham, J. R. (2011). Clinical implications of risk aversion: An online study of risk-avoidance and treatment utilization in pathological anxiety. Journal of Anxiety Disorders., 25, 840-848. https://doi.org/10.1016/j.janxdis.2011.04.008.

Mac Donald, A, P. (1970). Revised scale for ambiguity Tolerance: Reliability and Validity. Psychological Reports. https://doi.org/10. 2466/pr0.1970.26.3.791.

Maner, J. K., \& Schmidt, N. B. (2006). The role of risk avoidance in anxiety. Behavior Therapy, 37, 181-189. https://doi.org/10.1016/j. beth.2005.11.003.
Mauri, A., Tomas, M., Ongaro, G., \& Riccato, O. (2018). Perceived wellbeing and mindfulness practices in hospital patients. Psicologia della Salute, 1, 146-159. https://doi.org/10.3280/PDS2018-001009.

Mazza, C., Ricci, E., Biondi, S., Colasanti, M., Ferracuti, S., Napoli, C., \& Roma, P. (2020). A nationwide survey of psychological distress among italian people during the covid-19 pandemic: Immediate psychological responses and associated factors. International Journal of Environmental Research and Public Health, 17(9), 3165. https://doi.org/10.3390/ijerph17093165.

McLain, D. L. (1993). The mstat-i: A new measure of an individual's tolerance for ambiguity. Educational and Psychological Measurement., 53, 183-189. https://doi.org/10.1177/ 0013164493053001020.

Morelli, M., Cattelino, E., Baiocco, R., Trumello, C., Babore, A., Candelori, C., \& Chirumbolo, A. (2020). Parents and children during the COVID-19 lockdown: The influence of parenting distress and parenting self-efficacy on Children's emotional well-being. Frontiers in Psychology, 11. https://doi.org/10.3389/fpsyg.2020. 584645.

Nussbaumer-Streit, B., Mayr, V., Dobrescu, A. I., Chapman, A., Persad, E., Klerings, I., et al. (2020). Quarantine alone or in combination with other public health measures to control COVID-19: A rapid review. The Cochrane database of systematic reviews. https://doi. org/10.1002/14651858.CD013574.

Papini, D. R., Farmer, F. F., Clark, S. M., Micka, J. C., \& Barnett, J. K. (1990). Early adolescent age and gender differences in patterns of emotional self-disclosure to parents and friends. Adolescence, 25(100), 959.

Park, S, C., \& Park, Y, C. (2020). Secondary emotional reactions to the Covid-19 outbreak should be identified and treated in Korea. Journal of Korean Medical Science. https://doi.org/10.3346/JKMS.2020.35. E161, 35.

Petrocchi, S., Levante, A., Bianco, F., Castelli, I., \& Lecciso, F. (2020). Maternal distress/coping and Children's adaptive behaviors during the COVID-19 lockdown: Mediation through Children's emotional experience. Frontiers in Public Health, 8, 587833. https://doi.org/ 10.3389/fpubh.2020.587833.

Petrocchi, S., Bernardi, S., Malacrida, R., Traber, R., Gabutti, L., \& Grignoli, N. (2021). Empathy predicts self-isolation behaviour acceptance during coronavirus risk exposure. https://doi.org/10. 31234/OSF.IO/H9YTS.

Pfattheicher, S., Nockur, L., Böhm, R., Sassenrath, C., \& Petersen, M. B. (2020). The emotional path to action: Empathy promotes physical distancing and wearing of face masks during the COVID-19 pandemic. Psychological Science, 31(11), 1363-1373. https://doi.org/ 10.1177/0956797620964422.

Pierro, A., Mannetti, L., Converso, D., Garsia, V., Miglietta, A., Ravenna, M., \& Rubini, M. (1995). Caratteristiche strutturali della versione italiana della scala di bisogno di chiusura cognitiva. TPM, 2(3-4), $125-141$.

Pirutinsky, S., Cherniak, A. D., \& Rosmarin, D. H. (2020). COVID-19, mental health, and religious coping among American orthodox Jews. Journal of Religion and Health, 59(5), 2288-2301. https:// doi.org/10.1007/s10943-020-01070-z.

Powell, P. A. (2018). Individual differences in emotion regulation moderate the associations between empathy and affective distress. Motivation and Emotion., 42, 602-613. https://doi.org/10.1007/ s11031-018-9684-4.

Prout, T, A., Zilcha-Mano, S., Aafjes-van Doorn, K., Békés, V., Christman-Cohen, I., Whistler, K., Kui T., di Giuseppe M. (2020). Identifying predictors of psychological distress during COVID-19: A machine learning approach. Frontiers in Psychology, 11. https:// doi.org/10.3389/fpsyg.2020.586202.

Reich, J. W., Johnson, L. M., Zautra, A. J., \& Davis, M. C. (2006). Uncertainty of illness relationships with mental health and coping 
processes in fibromyalgia patients. Journal of Behavioral Medicine, 29, 307-316. https://doi.org/10.1007/s10865-006-9054-7.

Ritov, I., \& Baron, J. (1990). Reluctance to vaccinate: Omission bias and ambiguity. Journal of Behavioral Decision Making., 3, 263-277. https://doi.org/10.1002/bdm.3960030404.

Riva, S., Iannello, P., Pravettoni, G., \& Antonietti, A. (2015). What are judgment skills in health literacy? A psycho-cognitive perspective of judgment and decision-making research. Patient Preference and Adherence, 9, 1677. https://doi.org/10.2147/PPA.S90207.

Rosen, N. O., \& Knäuper, B. (2009). A little uncertainty goes a long way: State and trait differences in uncertainty interact to increase information seeking but also increase worry. Health Communication., 24, 228-238. https://doi.org/10.1080/10410230902804125.

Rosen, N. O., Knäuper, B., \& Sammut, J. (2007). Do individual differences in intolerance of uncertainty affect health monitoring? Psychology and Health., 22, 413-430. https://doi.org/10.1080/ 14768320600941038.

Rossi, A., Panzeri, A., Pietrabissa, G., Manzoni, G, M., Castelnuovo, G., \& Mannarini, S. (2020). The anxiety-buffer hypothesis in the time of COVID-19: When self-esteem protects from the impact of loneliness and fear on anxiety and depression. Frontiers in Psychology, 11. https://doi.org/10.3389/fpsyg.2020.02177.

Rubin, G, J., \& Wessely, S. (2020). The psychological effects of quarantining a city. The BMJ. https://doi.org/10.1136/bmj.m313.

Salvi, C., Iannello, P., Cancer, A., McClay, M., Rago, S., Dunsmoor, J. E., \& Antonietti, A. (2021). Going viral: How fear, socio-cognitive polarization and problem-solving influence fake news detection and proliferation during COVID-19 pandemic. Frontiers in Communication, 5, 562588. https://doi.org/10.3389/fcomm.2020.562588.

Sebri, V., Cincidda, C., Savioni, L., Ongaro, G., \& Pravettoni, G. (2021). Worry during the initial height of the COVID-19 crisis in an Italian sample. Journal of General Psychology. https://doi.org/10.1080/ 00221309.2021.1878485, 1, 33.

Shigemura, J., Ursano, R. J., Morganstein, J. C., Kurosawa, M., \& Benedek, D. M. (2020). Public responses to the novel 2019 coronavirus (2019-nCoV) in Japan: Mental health consequences and target populations. Psychiatry and Clinical Neurosciences., 74, 281-282. https://doi.org/10.1111/pcn.12988.

Tausczik, Y., Faasse, K., Pennebaker, J. W., \& Petrie, K. J. (2012). Public anxiety and information seeking following the H1N1 outbreak: Blogs, newspaper articles, and Wikipedia visits. Health Communication., 27, 179-185. https://doi.org/10.1080/10410236. 2011.571759
Turner, M. M., Rimal, R. N., Morrison, D., \& Kim, H. (2006). The role of anxiety in seeking and retaining risk information: Testing the risk perception attitude framework in two studies. Human Communication Research., 32, 130-156. https://doi.org/10.1111/j. 1468-2958.2006.00006.x.

VandenBos, G. R. (2015). APA dictionary of psychology, second edition. Choice Reviews Online.

Viscusi, W. K. (1997). Alarmist decisions with divergent risk information. Economic Journal., 107, 1657-1670. https://doi.org/10.1111/j. 1468-0297.1997.tb00073.x.

Viscusi, W. K., Magat, W. A., \& Huber, J. (1991). Communication of ambiguous risk information. Theory and Decision, 31, 159-173. https://doi.org/10.1007/BF00132991.

Wang, C., Pan, R., Wan, X., Tan, Y., Xu, L., McIntyre, R. S., Choo, F. N., Tran, B., Ho, R., Sharma, V. K., \& Ho, C. (2020). A longitudinal study on the mental health of general population during the COVID19 epidemic in China. Brain, Behavior, and Immunity., 87, 40-48. https://doi.org/10.1016/j.bbi.2020.04.028.

Weber, E, U., Blais, A, R., \& Betz, N, E. (2002). A domain-specific riskattitude Scale: Measuring Risk Perceptions and Risk Behaviors. Journal of Behavioral Decision Making. https://doi.org/10.1002/ bdm. 414 .

Webster, D. M., \& Kruglanski, A. W. (1994). Individual differences in need for cognitive closure. Journal of Personality and Social Psychology., 67, 1049-1062. https://doi.org/10.1037/0022-3514. 67.6.1049.

Wechsler, B. (1995). Coping and coping strategies: A behavioural view. Applied Animal Behaviour Science, 43(2), 123-134. https://doi.org/ 10.1016/0168-1591(95)00557-9.

WHO, W. H. O. (2020). Novel Coronavirus(2019-nCoV). Situation Report - 13. https://www.who.int/docs/defaultsource/coronaviruse/situation-reports/20200202-sitrep-13-ncovv3.pdf

Witte, K. (1992). Putting the fear back into fear appeals: The extended parallel process model. Communication Monographs., 59, 329-349. https://doi.org/10.1080/03637759209376276.

Zhao, Y., Cheng, S., Yu, X., \& Xu, H. (2020). Chinese public's attention to the COVID-19 epidemic on social media: Observational descriptive study. Journal of Medical Internet Research., 22, e18825. https://doi.org/10.2196/18825.

Publisher's Note Springer Nature remains neutral with regard to jurisdictional claims in published maps and institutional affiliations. 